\title{
Physicians Attitudes Towards Abortion of Fetuses with Severe Disabilities in Jordan
}

\author{
Fajer Ibrahim Qutishat ${ }^{1}$, Khaleel Mahmoud Alzyood ${ }^{2}$ \& Nahida Mohsin AbdulHadi ${ }^{3}$ \\ ${ }^{1}$ The World Islamic Science and Education University, Jordan \\ ${ }^{2}$ Maria Den Braven Center, Jordan \\ ${ }^{3}$ Minister of Education, Jordan \\ Correspondence: Fajer Ibrahim Qutishat, The World Islamic Science and Education University, Jordan. E-mail: \\ fajer.qutishat@gmail.com
}

Received: November 23, 2020

Accepted: December 4, 2020

Online Published: December 30, 2020

doi:10.5539/ass.v17n1p34

URL: https://doi.org/10.5539/ass.v17n1p34

\begin{abstract}
This study aimed to know the attitudes of physicians toward abortion of fetuses with severe disabilities in Jordan, where the attitudes is investigated by taking into account six variables (gender, age, major, years of experience, workplace, and marital status). In order to achieve the aims of this study, a questionnaire of attitudes toward abortion of fetuses with severe disabilities were used to collect data from 199 physicians. The results showed that the arithmetic mean of physicians toward abortion of fetuses with severe Disabilities in Jordan in total degree was in intermediate degree with arithmetic mean (2.01) and standard deviation (0.28). Also it indicated that there no statistically significant differences between the physicians in the attitudes toward abortion of fetuses with severe disabilities due to gender, age, and the workplace. But there are statistically significant differences between physicians in the attitudes due to major, years of experience, and marital status.
\end{abstract}

Keywords: attitudes, physicians, abortion, severe disabilities, Jordan

\section{Introduction}

The subject of abortion is one of the topics studied from several dimensions: Medical, social, psychological, religious, and even legislative statutory dimension. Taking into consideration the groups of society included in it: physicians, families, mothers, and also lawyers and clergy; each from a different perspective. Abortion is defined as the termination of pregnancy by the removal or expulsion from the uterus of a fetus or embryo prior to viability. An abortion can occur spontaneously, in which case it is usually called a miscarriage, or it can be purposely induced. The term abortion most commonly refers to the induced abortion of a human pregnancy (Shah, 2009; Sibomana, Byiringiro, Uwanyagasani, \& Mpawenimana, 2013). There are restrictions governing the issue of abortion especially in the Middle East and North Africa (MENA) as Dabash and Roudi-Fahimi 2008 mentioned: laws may require the authorization of several physicians or require the husband's approval, in addition to Physicians may lack knowledge of the law because it is unclear.

\subsection{Introduce the Problem}

The birth of a child with a disability has its economic, psychological and social implications for both the child himself, his family and the whole society. Not to mention that these effects increase with the severity of disability Yahiya (2016). And the medical progress contributed positively to the possibility of detecting those with severe disabilities in the stages of pregnancy and even early ones, which may contribute to the possibility of early intervention as much as possible. Where many of sophisticated techniques can now use as prenatal screening programs on pregnant women's to detected if the fetus have any neural tube defects and Down syndrome as an example Faden et al. (1987).

The issue of abortion is not considered one of the issues raised a lot in Jordanian society, neither in terms of social nor medical, especially if the fetus is a person with severe disabilities, not to mention the effect of direct religion in determining the nature of trends towards abortion. Beyond law and religion, this study attempts to survey physicians' attitudes toward abortion of severely disabled fetuses. 


\subsection{Significance of the Study}

The significance of this study is derived from the importance of the issues about the attitudes of physicians towards abortion of fetuses with severe disabilities in Jordan; especially that, this is one of the topics that were not addressed in the literature of children with disabilities in Jordan, especially severe ones. The study also contributes to the study of differences in the attitudes of Jordanian physicians towards abortion according to the study variables.

\subsection{Study Objectives}

This study aimed to:

A. Investigate the attitudes of physicians towards abortion of fetuses with severe disabilities in Jordan.

B. Investigate the differences of attitudes of physicians towards abortion of fetuses with severe disabilities in Jordan according to: (gender of physicians, age, major, years of experience, workplace, marital status).

\subsection{Study Questions}

The current study is seeking to answer the following questions:

1. What are the attitudes of physicians towards abortion of fetuses with severe disabilities in Jordan?

2. Are there any significant statistical differences at the level of $(\alpha \leq 0.05)$ in the attitudes of physicians towards abortion of fetuses with severe disabilities in Jordan according to the variables (gender, age, major, experience, workplace, marital status)?

\subsection{Definition of Terms}

\subsubsection{Attitudes}

Attitude is an individual's disposition to react to certain object, behavior, person, institution, event or other discriminable aspect of the individual's world (Ajzen, 1993).

\subsubsection{Abortion}

Abortion is defined as the termination of pregnancy by the removal or expulsion from the uterus of a fetus or embryo prior to viability. An abortion can occur spontaneously, in which case it is usually called a miscarriage, or it can be purposely induced. The term abortion most commonly refers to the induced abortion of a human pregnancy (Shah, 2009).

\subsubsection{Severe Disabilities}

Persons with severe disabilities are: "include individuals of all ages who require extensive ongoing support in more than one major life activity in order to participate in integrated community settings and to enjoy a quality of life that is available to citizens with fewer or no disabilities. Support may be required for life activities such as mobility, communication, self-care, and learning as necessary for independent living, employment and selfsufficiency" (Adopted by TASH, Meyer, Peck, \& Brown, 1991, p. 19).

\subsection{Limitation of the Research}

The study limits are as follows:

Human Limits: The performance of this study was limited to the age group of 25 years and over from general practitioners and gynecologists distributed between the government and private sectors

Time limits: The questionnaire was applied in the time period between 1/12/2019 - 1/3/2020.

Locative limits: the study was limited to physicians from the Jordanian capital: Amman.

\subsection{Previous Studies}

Faden, Chwalow, Quaid, Chase, Lopes, Leonard, and Holtzman, (1987) they studied the attitudes of 490 pregnant women toward the abortion of defective fetuses. Three hundred of these women were participating in a prenatal screening program for neural tube defects. Although theoretical accounts of the effects of behavior on attitude would suggest that participation in a screening program would affect abortion attitudes, evidence in support of such an association was weak. The overwhelming majority of women, regardless of whether they had participated in the screening program, believed that women are justified in having an abortion in the face of fetal abnormality. There was a sharp increase in the number of screening program participants who said they would have an abortion when the probability of the fetus being affected with a neural tube defect rose from 95 per cent to 100 per cent. 
Mekuriaw Sintayehu, Mesay Robel, Dereje Adissalem, Kumalo Abera, Feyissa Mulugeta, and Henok, Andualem. (2015) the study assess the knowledge, attitude and practice towards safe abortion among 422 female students of MizanTepi University, Southwest, Ethiopia. Majority of the respondents $382(90.52 \%)$ reported that they had ever heard about safe abortion. More than half $123(58.37 \%)$ of them reported mass media as their main sources of information. Among the respondents, 225 (53.31\%) know the reason to attend safe abortion and 418 (99.05\%) know about family planning methods. Many of the respondents $313(74.17 \%)$ had positive attitude towards safe abortion and $128(40.84 \%)$ said safe abortion is necessary to prevent school disruption. From the respondents 5 $(1.18 \%)$ reported that they ever practiced safe abortion and $3(60 \%)$ of them mentioned health center as place where the procedure was performed. From those who practiced abortion $1(20 \%)$ of them complain problem after the procedure and that complain was pain.

Seyede, Somayeh, Farideh, Baharak, and Javad (2016), this study aimed to evaluate the attitude of women of reproductive age towards induced abortion. The study was performed on 450 women of reproductive age in Fatemieh Hospital in Hamedan, Iran using abortion attitude scale consisting of five sections: socioeconomic status, family status, maternal and fetal health status, psychocultural background, and fertility status. Results induced abortion had no significant relationship with family status, maternal and fetal health, and fertility domains $(82.1 \%, 77.3 \%$, and $64.4 \%$, respectively). On the other hand, a relationship was observed between induced abortion and socioeconomic and psychocultural domains of the majority of the participants $(61.8 \%$ and $56 \%$, respectively). That's mean results indicated a strong belief in the majority of the participants in psychocultural and socioeconomic domains as the most significant predictive factors for induced abortion.

Rodaina (2016). This study aimed to know the attitudes of Jordanians people toward abortion deformed fetuses, and it aimed to investigate the effect of some variables on these attitudes. In order to achieve the aims of this study, a questionnaire of attitudes toward abortion deformed fetuses were used to collect data from 800 persons (344 males and 456 females). The results showed that the percentage of Jordanians people who refused abortion deformed fetuses is $(43.5 \%)$. Also it indicated that there are statistically significant differences between the Jordanians people in the attitudes toward abortion deformed fetuses due to gender, and the differences favored to males. Also there are no statistically significant differences between Jordanians people in the attitudes due to (age, educational level \& existence of a disability in the individual's family).

\section{Method and Procedures}

\subsection{Research Population and Samples}

To describe the characteristics of the study sample, the frequencies and percentages were extracted. The study sample consisted of 199 individuals distributed according to the study variables (gender, age, major, experience, workplace, marital status) as follows:

Table 1. Sample Table

\begin{tabular}{cccc}
\hline Variable & Variable categories & Number & Percentage \\
\hline \multirow{3}{*}{ Gender } & Male & 86 & 43.2 \\
& female & 113 & 56.8 \\
& Total & 199 & 100.0 \\
\hline \multirow{3}{*}{ Years of experience } & $1-5$ & 49 & 24.6 \\
& $6-10$ & 88 & 44.2 \\
& $11-15$ & 36 & 18.1 \\
& $\geq 16$ & 26 & 13.1 \\
& Total & 199 & 100.0 \\
\hline \multirow{3}{*}{ Age } & $25-30$ & 37 & 18.6 \\
& $31-36$ & 75 & 37.7 \\
& $37-42$ & 43 & 21.6 \\
& $\geq 43$ & 44 & 22.1 \\
& Total & 199 & 100.0 \\
\hline \multirow{2}{*}{ Major } & General Practitioner & 126 & 63.3 \\
& Gynecologist & 73 & 36.7 \\
& Total & 199 & 100.0 \\
\hline
\end{tabular}




\begin{tabular}{cccc}
\hline \multirow{3}{*}{ Workplace } & Government Sector & 111 & 55.8 \\
& Private Sector & 88 & 44.2 \\
& Total & 199 & 100.0 \\
\hline \multirow{3}{*}{ Marital status } & Single & 89 & 44.7 \\
& Married & 87 & 43.7 \\
& Divorced & 20 & 10.1 \\
& Widow/er & 3 & 1.5 \\
\hline
\end{tabular}

\subsection{Research Tool}

To achieve the purpose of the study, the questionnaire used in the study in its final version consisted of two parts: it includes in the first part of it is general information related to the individuals of the study sample and study variables (gender, age, major, years of experience, workplace, and marital status). The second part of it includes 45 paragraphs, and the directions were measured using a triple rating scale $(1,2,3)$ where 1 indicates I Disagree, 2 Neutral, and I Agree.

\subsubsection{Reliability of the Study}

To check the reliability of the tool Cronbach's Alpha coefficient was used; totaling (0.88), this value is accepted in order to achieve the aims of this study.

\subsubsection{Validity of the Study}

The researchers used more than one indicator to explore the validity of the tool, those are:

\subsubsection{Raters Validity}

To check the validity of the scale and its suitability to achieve the aims of the study, it was presented in its first form to a jury of raters of faculty members in Jordanian universities specialized in medicine and special education. They were asked to rate the scale within its items, phrasing and clarity as well as adding and deleting any unnecessary items; researchers adopted $80 \%$ criteria to modify the scale, and all comments were reviewed and the scale was modified.

\subsubsection{Internal Consistency}

The homogeneity of the scale was verified internally using the internal consistency method, which is one of the construct validity methods, where the correlation coefficient was found for each of the scale paragraphs with the total score of the scale, and Table 2 presents the results of that.

Table 2. Correlation Coefficient with the Total Degree of the Scale

\begin{tabular}{cccccc}
\hline Item & Correlation Coefficient & Item & Correlation Coefficient & Item & Correlation Coefficient \\
\hline 1 & $0.59^{*}$ & 16 & $0.55^{*}$ & 31 & $0.83^{*}$ \\
2 & $0.71^{*}$ & 17 & $0.39^{*}$ & 32 & $0.46^{*}$ \\
3 & $0.62^{*}$ & 18 & $0.48^{*}$ & 33 & $* 0.42$ \\
4 & $0.49^{*}$ & 19 & $0.72^{*}$ & 34 & $* 0.41$ \\
5 & $0.61^{*}$ & 20 & $* 0.83$ & 35 & $* 0.50$ \\
6 & $0.80^{*}$ & 21 & $* 0.35$ & 36 & $* 0.76$ \\
7 & $* 0.70$ & 22 & $0.61 *$ & 37 & $0.69^{*}$ \\
8 & $* 0.40$ & 23 & $* 0.57$ & 38 & $* 0.77$ \\
9 & $0.59^{*}$ & 24 & $0.41^{*}$ & 39 & $* 0.81$ \\
10 & $* 0.68$ & 25 & $0.71^{*}$ & 40 & $* 0.55$ \\
11 & $0.46^{*}$ & 26 & $* 0.73$ & 41 & $* 0.48$ \\
12 & $0.75^{*}$ & 27 & $* 0.53$ & 42 & $* 0.61$ \\
13 & $* 0.81$ & 28 & $* 0.59$ & 43 & $* 0.70$ \\
14 & $0.53^{*}$ & 29 & $* 0.65$ & 44 & $* 0.55$ \\
15 & $0.69^{*}$ & 30 & $* 0.48$ & 45 & $* 0.63$ \\
\hline
\end{tabular}

* Significance at the level of $\alpha \leq 0.05$ 
Table 2 shows that all correlation coefficients are statistically significant at the level of $\alpha \leq 0.05$ indicating the validity of the internal constancy of the scale.

\section{Results and Discussion}

This part contains the results of the research and its discussion according the questions as well as the recommendations, this was done through carting out statistical measures by using SPSS package. Following the results of the study:

\subsection{To Answer the First Question: What Are the Attitudes of Physicians Towards Abortion of Fetuses with Severe Disabilities in Jordan?}

To answer this question means and standard deviations were calculated for the responses of the sample Physicians- on the study scale. Table 3 shows the results.

Table 3. Balanced Means and Standard Deviators of the Attitudes of Physicians towards Abortion of Fetuses with Severe Disabilities in Jordan

\begin{tabular}{|c|c|c|c|c|c|}
\hline No & Rank & Item & M & SD & Level \\
\hline 17 & 1 & I consider that making an abortion decision is useful for using aborted fetuses in scientific research & 2.58 & 0.60 & High \\
\hline 36 & 2 & The profession of the doctor is humane and this does not contradict the decision to make an abortion & 2.57 & 0.63 & High \\
\hline 27 & 3 & $\begin{array}{l}\text { The continued pregnancy of a mother with a fetus diagnosed with a severe disability is tired organically } \\
\text { and psychologically }\end{array}$ & 2.46 & 0.63 & High \\
\hline 35 & 4 & Continuing pregnancy in the hope that the fetus will heal or a magical solution to severe disability is futile & 2.43 & 0.67 & High \\
\hline 6 & 5 & $\begin{array}{l}\text { From a medical point of view: the fact that the mother continues to become pregnant with a fetus with } \\
\text { severe disabilities is dangerous for her }\end{array}$ & 2.36 & 0.69 & High \\
\hline 7 & 6 & There is no future for a fetus with severe disabilities, and it is an appropriate decision to abort it & 2.34 & 0.69 & High \\
\hline 34 & 7 & $\begin{array}{l}\text { The error rate for diagnosing severe disability is very small, which makes it easier to make an abortion } \\
\text { decision without feeling guilty }\end{array}$ & 2.30 & 0.70 & Average \\
\hline 42 & 8 & $\begin{array}{l}\text { The abortion of fetuses with severe disabilities medically contributes to working in the future pregnancy } \\
\text { with a healthy fetus }\end{array}$ & 2.28 & 0.71 & Average \\
\hline 44 & 9 & It considered that aborting the fetus with severe disabilities is a kind of euthanasia him & 2.25 & 0.67 & Average \\
\hline 5 & 10 & Abortion for a fetus with severe disabilities has a benefit for the fetus first and foremost & 2.24 & 0.68 & Average \\
\hline 25 & 11 & $\begin{array}{l}\text { By virtue of my work: I think that a fetus with severe disabilities must be aborted, especially since I know } \\
\text { the suffering of families with children with severe disabilities }\end{array}$ & 2.20 & 0.73 & Average \\
\hline 26 & 12 & $\begin{array}{l}\text { I support a fetus with a severe disability to have a chance to live in the hope that there will be treatment in } \\
\text { the future }\end{array}$ & 2.19 & 0.69 & Average \\
\hline 43 & 13 & $\begin{array}{l}\text { From a medical point of view, the expected results of aborting fetuses with severe disabilities are more } \\
\text { than what we expect }\end{array}$ & 2.18 & 0.72 & Average \\
\hline 8 & 14 & $\begin{array}{l}\text { In my view: the abortion of fetuses with severe disabilities inconsistent with the ethics of the medical } \\
\text { profession }\end{array}$ & 2.17 & 0.82 & Average \\
\hline 15 & 15 & The decision to abortion is a shared responsibility of the family and the doctor & 2.16 & 0.71 & Average \\
\hline 33 & 16 & $\begin{array}{l}\text { Even with medical advances, there is no definitive treatment for severe disability if there is hope after the } \\
\text { birth that the baby will recover }\end{array}$ & 2.15 & 0.70 & Average \\
\hline 13 & 17 & $\begin{array}{l}\text { The best option is to make an abortion decision for a fetus with a severe disability during the first three } \\
\text { months of pregnancy }\end{array}$ & 2.14 & 0.68 & Average \\
\hline 45 & 18 & $\begin{array}{l}\text { For the possibility of error in the diagnosis, even a small percentage, I do not recognize the necessity of } \\
\text { abortion }\end{array}$ & 2.13 & 0.72 & Average \\
\hline 41 & 19 & Medically, the decision to have an abortion should be the last possible solution, not the first & 2.12 & 0.70 & Average \\
\hline 14 & 20 & $\begin{array}{l}\text { As a physician, I understand the meaning of the birth of a child with severe disability and its medical } \\
\text { implications, and I support his abortion }\end{array}$ & 2.10 & 0.64 & Average \\
\hline 40 & 21 & Taking an abortion decision under medical supervision reduces illegal abortions & 2.05 & 0.70 & Average \\
\hline 16 & 22 & $\begin{array}{l}\text { I am not with abortion under any reason, given that abortion of the fetus is weak by faith and by its good } \\
\text { and bad }\end{array}$ & 2.03 & 0.66 & Average \\
\hline 23 & 23 & I think that the fetus has the right to life, even if it has severe disabilities & 2.02 & 0.66 & Average \\
\hline 32 & 24 & $\begin{array}{l}\text { I think that people with severe disabilities are not desirable by society and it is correct to abort them } \\
\text { before birth }\end{array}$ & 1.99 & 0.61 & Average \\
\hline 24 & 25 & I am against abortion fetus with severe disabilities, for legal considerations & 1.97 & 0.70 & Average \\
\hline 30 & 26 & I think physicians can use aborted fetuses to determine the causes of severe disability, which will improve & 1.96 & 0.81 & Average \\
\hline
\end{tabular}


disability prevention programs

3927 The abortion of fetuses with a severe disability is similar in his idea as the early examination of diseases, both of which prevent something before it happens

$1.94 \quad 0.79$ Average

I support the decision to abort because the birth of this fetus will cost the state a lot of financial burdens as

328 a result of his severe disability

$1.93 \quad 0.73$ Average

I can't agree to the decision to have an abortion because there is a percentage of severe disabilities that do not appear during pregnancy

1230 One way of protecting it is to consider abortion by physicians for a fetus with severe disabilities

$1.92 \quad 0.71$ Average

From a scientific point of view: Having a child with

.91 0.70 Average

1131 being repeated in the coming loads

2232 It is wise that the decision to abort fetuses with severe disabilities is easy because of the severe disability

1.860 .83 Average

1.810 .64 Average

2933 Fetal abortion with severe disabilities may play a role in reducing the percentage of people with disabilities in general in society

$38 \quad 34$ abortion fetuses with severe disabilities reduces the proportion of genetic diseases in society

1.760 .88 Average

35

Even if it is decided to abort the fetus, I try to persuade the family to refrain from this decision

1.740 .86 Average

1.730 .56 Average

236

One of my professional duties as a doctor is to assist the family in making an abortion decision if the fetus is severe disability

1.710 .76 Average

If $\mathrm{i}$ had the choice, I would insist on aborting the fetus at the same moment he was diagnosed with severe disability

$1.70 \quad 0.59$ Average

Making an abortion decision is in line with the doctor's department in preserving human life in all its

$\begin{array}{lll}37 & 38 & \text { roles and saving her from illness and pain } \\ 10 & 39 & \text { Abortion has benefits in reducing the effects of a severely disabled child in the community in the future }\end{array}$

1.690 .87 Average

$1.67 \quad 0.87$ Average

940 Painful to making a decision to abortion fetus with severe disability, but it is a sound decision at all levels

941 Making an abortion decision for fetus with severe disabilities is a form of early intervention and Making an abortion decision for fetus with
improving the level of health care in society

2042 It is inhumane to support abortion of a fetus, even if it has severe disabilities

1843 Deciding to have an abortion is a form of genetic counseling

$1.66 \quad 0.79$ Average

$\begin{array}{lll}1.63 & 0.89 \quad \text { Low }\end{array}$

1.620 .66 Low

$\begin{array}{lll}1.59 & 0.83 \quad \text { Low }\end{array}$

I consider that abortion of the fetus, even if it is with severe disabilities, is an objection to the ruling of God

$1.58 \quad 0.70 \quad$ Low

I think that the death of a child with severe disability after birth is a less impact than taking a decision to abort it

1.410 .69 Low

(1)

Total

$2.01 \quad 0.28$ Average

Table 3 shows that the means of physicians attitudes towards abortion of fetuses with severe disabilities in Jordan was in an average level as a whole with a mean of (2.01) and standards deviation of (0.28), on items level, item (17) provided that (I consider that making an abortion decision is useful for using aborted fetuses in scientific research) ranked first with a mean of (2.58) and standard deviation of (0.60) with a high degree. Meanwhile, item (28) provided that (I think that the death of a child with severe disability after birth is a less impact than taking a decision to abort it) ranked last with a mean of (1.41) and standard deviation of (0.69) within a low degree.

To explore the indications of the means the researchers adopted the following criteria (less than 1.66 weak. From 1.66-2.33 average level. Higher than 2.33 high level).

For more interpretation for the first question: the results distributed between six items where the attitudes were high. While, item (34) was in an average level, and other five items were low from the while (45) items. The items of the high level showed the abortion from a medical point of views, as in item (17) which linked the abortion with the use of aborted fetuses in scientific research, this goes logically with the type of the sample in this study (Physicians) as their responses supported by items (26-27-35-6-7) respectively.

To confirm the result, physicians 'responses to items with a low means, such as item 20 , which was in a low level, but the paragraph states that it is inhuman to support abortion of the fetus even if it is one with severe disabilities, which reflects the physicians' pure scientific viewpoint in the study of abortion Fetuses with severe disabilities.

3.2 To Answer the Second Question Provided That: Are There Any Significant Statistical Differences at the Level of $(\alpha \geq 0.05)$ in the Attitudes of Physicians Towards Abortion of Fetuses with Severe Disabilities in Jordan According to the Variables (Gender, Age, Major, Experience, Workplace, Marital Status)? 
To answer this question Multiple ANOVA was used to investigate the differences in physicians attitudes towards abortion of fetuses with severe disabilities in Jordan according to the variables (gender, age, major, experience, workplace, marital status. Table 4 shows the results.

Table 4. Multiple ANOVA Results for the Differences in Physicians Attitudes towards Abortion of Fetuses with Severe Disabilities in Jordan According to the Variables

\begin{tabular}{cccccc}
\hline Variance & Squares & F & Means & F & Sig \\
\hline Gender & 0.000 & 1 & 0.000 & 0.004 & 0.952 \\
Age & 0.073 & 3 & 0.024 & 0.366 & 0.778 \\
Major & 0.434 & 1 & 0.434 & 6.511 & $0.012^{*}$ \\
Experience & 0.994 & 3 & 0.331 & 4.970 & $0.002^{*}$ \\
Work place & 0.050 & 1 & 0.050 & 0.752 & 0.387 \\
Marital status & 0.866 & 3 & 0.289 & 4.332 & $0.006^{*}$ \\
Error & 12.398 & 186 & 0.067 & & \\
Total & 816.162 & 199 & & & \\
Corrected total & 15.623 & 198 & & &
\end{tabular}

Sig: $\alpha \leq 0.05$

Table 4 shows that there were no significant statistical differences at the level of $\alpha \leq 0.05$ in physicians attitudes towards abortion of fetuses with severe disabilities in Jordan according to gender, age and work place variables. Meanwhile, there were significant statistical differences at the level of $\alpha \leq 0.05$ in physician's attitudes towards abortion of fetuses with severe disabilities in Jordan according to major, experience and marital status. To explore the significance of those differences means were reviewed, as general physicians mean was (1.96), obstetrics and gynecology specialists (2.07). This indicates that the differences are in favor of a specialist in obstetrics and gynecology, and this may explain that the obstetrician and gynecologist is more related to the issue of abortion for people with severe disabilities and is more familiar with the effects of that from a medical point of view, which appeared in their responses to the scale used for the purposes of the study. As for the level of variables (experience, marital status) Scheffe' Test was used to explore the nature of differences as shown in Tables 5 and 6.

Table 5. Scheffe' Test Results for the Post-Comparisons According to Experience Variable

\begin{tabular}{cccccc}
\hline \multirow{2}{*}{ Means } & \multirow{2}{*}{$\begin{array}{c}\text { Experience } \\
\text { categories }\end{array}$} & $1-5$ & $6-10$ & $11-15$ & +16 \\
\cline { 3 - 6 } & $1-5$ & - & -0.02 & $-0.13^{*}$ & $-0.20^{*}$ \\
1.93 & $6-10$ & 0.02 & - & $-0.11^{*}$ & $-0.18^{*}$ \\
2.95 & $11-15$ & $0.13^{*}$ & $0.11^{*}$ & - & $-0.07^{*}$ \\
2.13 & +16 & $0.20^{*}$ & $0.18^{*}$ & $0.07^{*}$ & - \\
\hline
\end{tabular}

Sig: $\alpha \leq 0.05$

Table 5 showed that the differences were significant statistically in favor of physicians with longer experience (16+) followed by 11-15 years' experience physicians, and finally those of (10 years) experience. This may be explained by the fact that individuals with longer experience had more connection with the field of obstetrics and gynecology than those with less experience and who have not yet specialized, which is consistent with what was previously mentioned in that the differences are in favor gynecology and obstetrics than those general practitioners.

Table 6. Scheffe' Test Results for the Post-Comparisons According to Marital Status Variable

\begin{tabular}{cccccc}
\hline \multirow{2}{*}{ Means } & \multirow{2}{*}{ Marital Status } & \multicolumn{4}{c}{ Differences } \\
\cline { 3 - 6 } & & Single & Married & Divorced & Widowed \\
\hline 1.95 & Single & - & $-0.10^{*}$ & -0.02 & $-0.51^{*}$ \\
2.05 & Married & $0.10^{*}$ & - & $0.08^{*}$ & $-0.41^{*}$ \\
1.97 & Divorced & 0.02 & $-0.08^{*}$ & - & $-0.49^{*}$ \\
2.46 & Widowed & $0.51^{*}$ & $0.41^{*}$ & $0.49^{*}$ & - \\
\hline
\end{tabular}

Sig: $\alpha \leq 0.05$

Table 6 showed that the differences were significant statistically in favor of widowed category followed by married, and finally, divorced and single. This explains the connection of the marital status with the age and 
years of experience in work, as shown in Table 5 reflecting the physician answers in this field.

\section{Recommendations}

The researchers recommend conducting further studies on measuring attitudes towards abortion with its association with disability, whether by studying other target groups to measure their attitudes, or by studying other variables such as the disability category, as this topic in general is not common in the study in the Jordanian society.

The researchers also recommend conducting comparative studies between attitudes towards abortion of fetuses with disabilities from a medical, legal, social and economic point of views.

Furthermore, researchers recommended the need to conduct a qualitative study explaining the attitudes of the Jordanian society towards the abortion of severe disability people, in order to consider the opinions of all the Jordanian society in this issue.

\section{References}

Ajzen, I. (1993). New Directions in Attitude Measurement. New York: Walter de Gruyter.

Altarawneh, R. (2016). Attitudes of Jordanians People toward Abortion Deformed Fetuses. Journal of the College of Education, Al-Azhar University, 171(2), 369-387. https://doi.org/10.21608/JSREP.2016.48865

Dabash, R., \& Roudi-Fahimi, F. (2008). Abortion in the Middle East and North Africa. Population Reference Bureau.

Faden, R. R., Chwalow, A. J., Quaid, K., Chase, G. A., Lopes, C., Leonard, C., \& Holtzman, N. A. (1987). Prenatal Screening and Pregnant Women's Attitudes toward the Abortion of Defective Fetuses. American Journal of Public Health AJPH March, 77(3), 288-290. https://doi.org/10.2105/AJPH.77.3.288

Iqbal, S., \& Elisabeth, A. (2009). Unsafe Abortion: Global and Regional Incidence, Trends, Consequences, and Challenges. Journal of Obstetrics and Gynaecology Canada: JOGC, 31(12), 1149-1158. https://doi.org/10.1016/S1701-2163(16)34376-6

Mangal, S. K. (2007). Educating Exceptional Children: An Introduction to Special Education. PHI Learning Private. Limited. Delhi.

Seyede, M., Somayeh, K., Farideh, K., Baharak, M. S., \& Javad, F. (2016). Attitude of Reproductive Age Women Towards Factors Affecting Induced Abortion in Hamedan, Iran. Journal of Midwifery and Reproductive Health, 4(3), 696-703. https://doi.org/10.22038/JMRH.2016.7119

Sibomana, J. P., Byiringiro, F., Uwanyagasani, J., \& Mpawenimana, D. (2013). Abortion: Attitudes and Knowledge of Women in Reproductive Age in Rwanda. Rwanda Medical Journal RMJ, 70(3), 9-13.

Sintayehu, M., Robel, M., Adissalem, D., Abera, K., Mulugeta, F., \& Henok, A. (2015). Knowledge, Attitude and Practice towards Safe Abortion among Female Students of Mizan-Tepi University, South West Ethiopia. $J$ Women's Health Care, 4, 275. https://doi.org/10.4172/2167-0420.1000275

TASH (The Association for Persons with Severe Handicaps). (1991). Definition of the People TASH Serves. In L. H. Meyer, C. A. Peck, \& L. Brown (Eds.), Critical Issues in the Lives of People with Severe Disabilities. Baltimore: Brookes.

Yahiya, K. (2016). Counseling Families with Special Needs. Daralfiker: Jordan.

\section{Copyrights}

Copyright for this article is retained by the author(s), with first publication rights granted to the journal.

This is an open-access article distributed under the terms and conditions of the Creative Commons Attribution license (http://creativecommons.org/licenses/by/4.0/). 